THE INTERNATIONAL

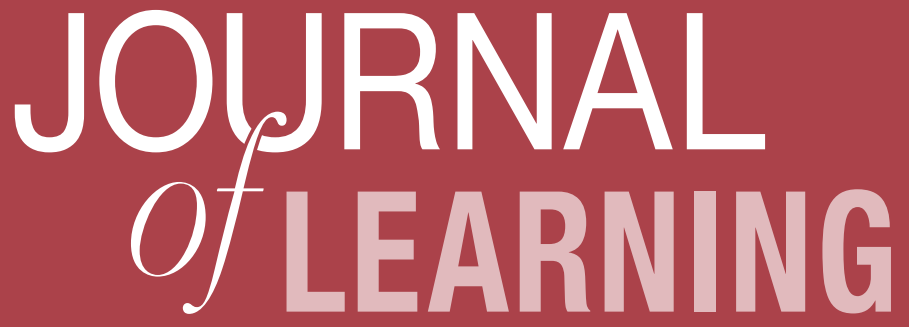

Volume 19

Values-based Learning: A Multi-level Approach to Ethical Leadership Development

Kandy Dayaram and Theodora Issa 
THE INTERNATIONAL JOURNAL OF

LEARNING http://www.thelearner.com

First published in 2014 in Champaign, Illinois, USA by Common Ground Publishing LLC www.CommonGroundPublishing.com

ISSN: $1447-9494$

(C) 2014 (individual papers), the author(s)

(c) 2014 (selection and editorial matter) Common Ground

All rights reserved. Apart from fair dealing for the purposes of study, research, criticism or review as permitted under the applicable copyright legislation, no part of this work may be reproduced by any process without written permission from the publisher. For permissions and other inquiries, please contact

<cg-support@commongroundpublishing.com>.

THE INTERNATIONAL JOURNAL OF LEARNING is peer-reviewed, supported by rigorous processes of criterion-referenced article ranking and qualitative commentary, ensuring that only intellectual work of the greatest substance and highest significance is published.

Typeset in Common Ground Markup Language using CGPublisher multichannel typesetting system

http://www.commongroundpublishing.com/software/ 


\title{
Values-based Learning: A Multi-level Approach to Ethical Leadership Development
}

\author{
Kandy Dayaram, Curtin University, Australia \\ Theodora Issa, Curtin University, Australia
}

\begin{abstract}
The paper aims to provide empirical evidence towards the ongoing research and debate on the nature of motivation and values that might impact ethical leadership. This paper presents the outcomes of a study that examines the relationship between personal values, consistency of actions and ethical leadership development, using crosssectional, longitudinal data from a leadership course. Data were collected from 32 postgraduate students at the beginning and end of the semester, testing for pre- and post-leadership intervention effects. In the pre-test, values such as integrity, honesty, trust, self-confidence and transparency were evident. Interventions, including personal reflection, formative learning and action research, had their impact on the way participants thought of ethical leadership, values and personal motivations. The results indicate that particular values that evolved post-test included trust, respect, integrity, self-awareness and responsibility, with empathy, honesty, respect, vision and responsibility remaining consistent throughout the study. These results are in contrast to some prior research in this area, including personal values, leader's actions and organizational values congruence. Our findings argue that multi-perspective, scaffolded learning is associated with significant levels of leadership reflection and self-awareness. Leaders with higher levels of reflection and self-awareness have significantly higher levels of motivation towards ethical behaviours that are generated from values.
\end{abstract}

Keywords: Ethical Leadership, Reflection, Self-Awareness, Personal Values

\section{Introduction}

I $\mathrm{t}$ is often contended that organizations constitute morally-complex environments, requiring members to possess levels of moral courage sufficient to promote their ethical action, while refraining from unethical actions when faced with temptations or pressures Hannah, Avolio, and Walumbwa (2011). Authentic leadership (of which ethical leadership is a dimension) is positively related to followers' display of moral courage, whereby the latter is fully mediated by the effects of authentic leadership on followers' ethical and pro-social behaviors (Hannah, Avolio, and Walumbwa 2011). Against the background of ongoing corporate scandals, Tumasjan, Strobel and Welpe, (2011) contend that the study of ethical leadership remains an important area of research which helps to understand the antecedents and consequences of ethical behaviour in organizations. They investigated how social distance influences ethical leadership evaluations and how, in turn, ethical leadership evaluations affect Leader-Member Exchange (LMX) after a leader's moral transgression. Bahl and Dadhich, (2011) on the other hand, not only explored the impact of ethical leadership and LMX on whistle blowing, but delved further to explore the moderating role of the moral intensity of the issue on such a relationship. Their results demonstrated that not only do ethical leadership and LMX predict whistle blowing, but these relationships are moderated by the moral intensity of the issue as well.

To date, the majority of research on 'ethical leadership' focuses predominantly on 'consequences' and neglects the 'antecedents' of such a type of leadership (Kalshoven, Den Hartog, and De Hoogh 2011). Kalshoven et al's (2011) work is insightful and makes a significant contribution as it simultaneously employs the Ethical Leadership Scale (ELS) and LMX and measures the leader and followers' perspectives of ethical leadership. Their results highlighted two leadership dimensions namely, conscientiousness and agreeableness). Traits, with conscientiousness being significantly clear when LMX was employed, and that 'emotional stability' is positively related to ethical leadership. Other study posits that culture affects 'ethical leadership'.

The International Journal of Learning

Volume 19, 2014, thelearner.com, ISSN: 14479494

(C) Common Ground, Kandy Dayaram and Theodora Issa, All Rights Reserved

Permissions: cg-support@commongroundpublishing.com 


\section{Values and Leadership}

Certain values such as independence, security and achievement are classified as preferred values as they only represent standards of importance or liking, with no element of right and wrong. On the other hand, work values are moral if they represent normative standards of right and wrong and ethical guidelines, such as integrity and honesty and raises questions such as: What is the intersection of character and leadership? How does the pressure to produce impact being a leader of character in the business world? Can character and leadership standards serve as a competitive advantage/disadvantage in business? In this respect, Muilenburg (2011) provides real-life evidence as to how underscoring the way beliefs, regarding the connection between character, leadership and business, are vital in today's business world. Character is regarded as being particularly important. Valle and Levy (2011) opine that leaders have the potential to be the agents of virtue or vice in organizations because they shape and influence the collective moral character of the organization. Thus, having a leader with a good character might lead to having an ethical leader who might be able to transform the organization for the better.

Values are important in ethical leadership. In their study of leadership, Holt and Marques (2012) focus on empathy in leadership. The findings of their study on business students demonstrate that empathy was often ranked lowest in importance in relation to values such as power. Holt and Marques' findings indicate the need for a paradigm shift in corporations as well as business schools in regard to leaders' required skills. This suggests a proactive approach from business schools to change the current paradigm. Against this background, this study aims to participate in this ongoing debate and research on ethical leadership and, through the limitations of this paper, we intend to explore the influence of leadership interventions and how values are formed and change over a period of time. To allow for a better understanding of the issue of ethical leadership, this paper will firstly discuss values-based leadership, moving onto a brief explanation of values and motivation. This would be followed by a brief discussion on the focus on ethical leadership, then we raise the question of malleability of values? Thereafter, we provide a brief discussion on the process of 'reflective thinking and self-awareness,' followed by methodology. In the results and discussion sections we will present a conceptual model on the pre, post and consistent values throughout the process. This would be useful in the ongoing research on 'ethical leadership' especially when studied in combination with that of Samar and Shoaf (2011) on 'professional ethical leadership,' including integrity, which is one of the values identified in this study.

Highlighting the issue of character and its importance to responsible or rather, ethical leadership, Basik and Keller (2011) and Demenchonok and Peterson (2009) argue that it is almost a cliché to suggest that today's environment for leadership is complex and dynamic. Indeed, there has likely never been a time when that was not the case, whether the context is business, education, military, parenting, politics or countless other domains. However, it would appear that the rate of change and complexity is on an exponential curve, increasingly elevated by rapid globalization, financial constraints, and technological advances. In addition, an everdiversifying population that enhances the violence that affects globalization, with its ethical dimension (Beck 2002) increases the complexity of the matters. Despite this, we can find comfort and challenge in the fact that some things hold constant - leadership is critical, and the character of those leading (and being led) has a tremendous impact on both processes and outcomes. Basik and Keller (2011) argue for the importance of 'leading with character in these turbulent seas of change'.

\section{The Process: Reflective Thinking and Self-awareness}

Reflective practice has emerged as an essential skill required for professional competence and is widely noted as a useful technique in developing leadership skills and competencies. For 
example, increasing attention has been given to promote reflective learning on the practice of professions such as education (Light, Calkins, \& Cox, 2009), medical professions (Gustafsson, Asp, \& Fagerberg, 2007; Mann, Gordon, \& MacLeod, 2007), and counselling (Collins, Arthur, \& Wong-Wylie, 2010; Stedmon \& Dallos, 2009). Various definitions of reflective learning were proposed in the literature (e.g. De la Harpe and Radloff, 1997; Dewy, 1933; Schön, 1983). Taken together, reflection involves the process of being aware of one's own behaviour, perceptions, cognitions, and emotions; analysing such experiences, evaluating their meaning and how they affect one's behaviour, interaction with the environment and with others; and planning further action based on what one has learnt from this evaluation. A number of models were developed on reflection, including Kolb’s (1984) model of experiential learning, Schön’s (1987, 1987; 1983) model of reflective practice, Mezirow's (1991) model of transformative learning, King and Kitchener's (1994) model of reflective judgment, and Moon's (1999) map of learning. Dewey (1933) argues that to be genuinely reflective, one must sustain a state of doubt, hesitation or perplexity in relation to the unprocessed materials of the experience, and search for materials that will resolve and clarify the doubt. Schön $(1987,1987 ; 1983)$ argues that a reflective learner engages in this critical evaluation of his or her own behaviour and improves his or her behaviour based on the insights gained from this evaluation. He proposed two modes of reflection in this process: reflection-in-action and reflection-on-action (Schön, 1991). Building upon Schön's (1991) model of reflective practice, Wong-Wylie (2006) expanded on these concepts by developing a third practice: reflection-on-self-in-action/reflection-on-self-on-action. This practice emphasises the uncovering dimensions of self, such as culture, worldview, ethnicity, and life experiences; and the understanding of how these deep-seated beliefs of oneself and values affect the way one understands, evaluates, and interacts with others.

In addition, to obtain genuine commitment from their followers, leaders need to create "resonance" in their interaction (Goleman, Boyatzis, \& McKee, 2002). Leaders need to constantly reflect on the emotional feelings and concerns of their subordinates, to communicate the vision in a way that is appealing to their personal goals, as well as constantly reflect on the impact of his or her words and behaviour on the followers.

Whilst leaders are usually faced with complex situations that are moral and value-laden (Schön, 1983), these challenges are political in nature and may not be effectively managed by technical and rational approaches to problem solving (Duignan, 1993). It is the leader's responsibility to resolve these value disputes, making judgments on conflicting ideas and to facilitate mediation between these different parties. Reflective leadership practice is required to understand conflicting views and the concerns of organization members in order to find a common ground for all parties; to surface personal values and convictions, and be critically aware of how these personal values colour their perceptions when judgments are being made. We then argue that constant reflection on personal values is needed for effective leadership and to ensure that the vision is driven by a genuine commitment to personal values. Against this background, our study therefore examines whether intervention processes that manipulate the level of self-awareness through reflection influences personal values that resonate around ethical leadership.

\section{Methodology}

Against this background, our study therefore examines whether intervention processes that manipulate the level of self-awareness through reflection influence personal values that resonate around ethical leadership. The following questions were asked: (1) List, define and prioritize your top 5 leadership values. (2) Write a concise description of what these 5 values mean to you and your day-to-day life. (3) Explain how you believe you obtained these values. For example, was it through a particular relationship with someone or a defining experience? (4) Explain why you prioritized your values in the above order. (5) Explain any pattern, theme, relationship, or 
logic behind all of your values? In other words, what meaning do these values have as a group beyond their individual meanings? (6) Describe how your values compare with your actions. Are they consistent or inconsistent with your actions? Why or why not? If they are inconsistent, what might you do to make your actions more consistent with your values? Where is it hardest for you to remain true to your values? What parts of these situations are the strongest deterrents to living out your leadership values? (7) Do your personal values conflict with the organization's official/stated and actual/operating values? If these contradict, how do they? How do you reconcile this difference to yourself? If they do not conflict, explain how they are consistent and what this means to your future in the organization? (8) What actions or behaviours do your values dictate with respect to your leadership? How will they affect who you will try to be as a leader and how you will act and make decisions as a leader? (9) Do you foresee a leadership situation in which your values might conflict with one another? Explain your answer. These will be discussed further in the following sections of the paper.

\section{Research Sample Participants}

This paper reports on the empirical findings of a postgraduate leadership course that employs reflective learning processes, including action learning aimed at increasing an individual's level of awareness. Thirty-two postgraduate students participated in this study. Whilst all the participants had some form of work experience, more than fifty per cent of the participants had some form of leadership experience. Whilst the leadership intervention program formed part of the leadership course, participation in this study was voluntary.

\section{Research Design}

The study comprised of a "pre-test/post-test"' experimental design to determine the effectiveness of the study. A "pre-test" baseline measure of leadership values (dependent variable) was carried out prior to the intervention program. Participants were asked to list, define and prioritize the leadership values they believed were most important to them. Using reflection, they needed to explain what, how and why these values were formed; any relevant defining experiences; how they prioritsed these values; and to explain any pattern, theme, relationship or logic behind those values. During the semester, the participants completed the intervention program, which formed a part of the action research program. The intervention program employed reflective learning and self-awareness to develop values which resonated with ethical leadership, such as leader as the self, moral development, transformational leadership, shaping culture, building and valuing diversity, the leadership vision, and strategy. In addition, an action-based research project undertaken by the participants formed a part of the intervention program. Action research is suggested as a means to generate a solution to practical problems and allows the researcher to engage in the research and to develop and implement activities in their teaching course (Metler 2006). Each participant interviewed a minimum of three real-world leaders occupying middle (managers) or top (directors, chief executive officers) leadership positions. The interview protocol comprised of questions asking how, why, and what leadership values they believed were most important to them. In addition, a minimum of three direct reports from each leader was surveyed. The direct reports were asked to reflect on the values they believed were most important to them, the values they believed their leader exhibited and if they believed there was congruence between their values, their leader's values and the organizations' values.

At the completion of the course, the same variables were used as a post-test. At this time participants were asked to reflect on their values using what they had studied during the course as well as their experience and results from their action research project. These were collected by the researcher and coded for matching results in the pre-test phase.

As this study was of a qualitative nature, content analysis was employed by researchers (Miles and Huberman 1994). Content analysis was deemed appropriate to gain an understanding 
of one's level of thought formation (Dose 1997). The researchers read and re-read prioritization and formation of values, as they listed and categorized the values. Results obtained from the pretest and the post-test measures were compared to determine whether the intervention program was effective in strengthening certain leadership values, and whether strengthening such values will result in a stronger preference for ethical leadership style among these participants.

\section{Results and Discussion}

At the beginning of the semester and prior to commencement of the leadership intervention program, the majority of participants, after a self-reflection exercise, noted five values as most important to them. When responding to the first and second questions (for example, list, define and prioritize your top 5 leadership values, and write a concise description of what these 5 values mean to you and your day-to-day life); the common themes of personal and work values that emerged from the participants were respect, integrity, honesty, trust, empathy, consideration, self-confidence, transparency and being open-minded.

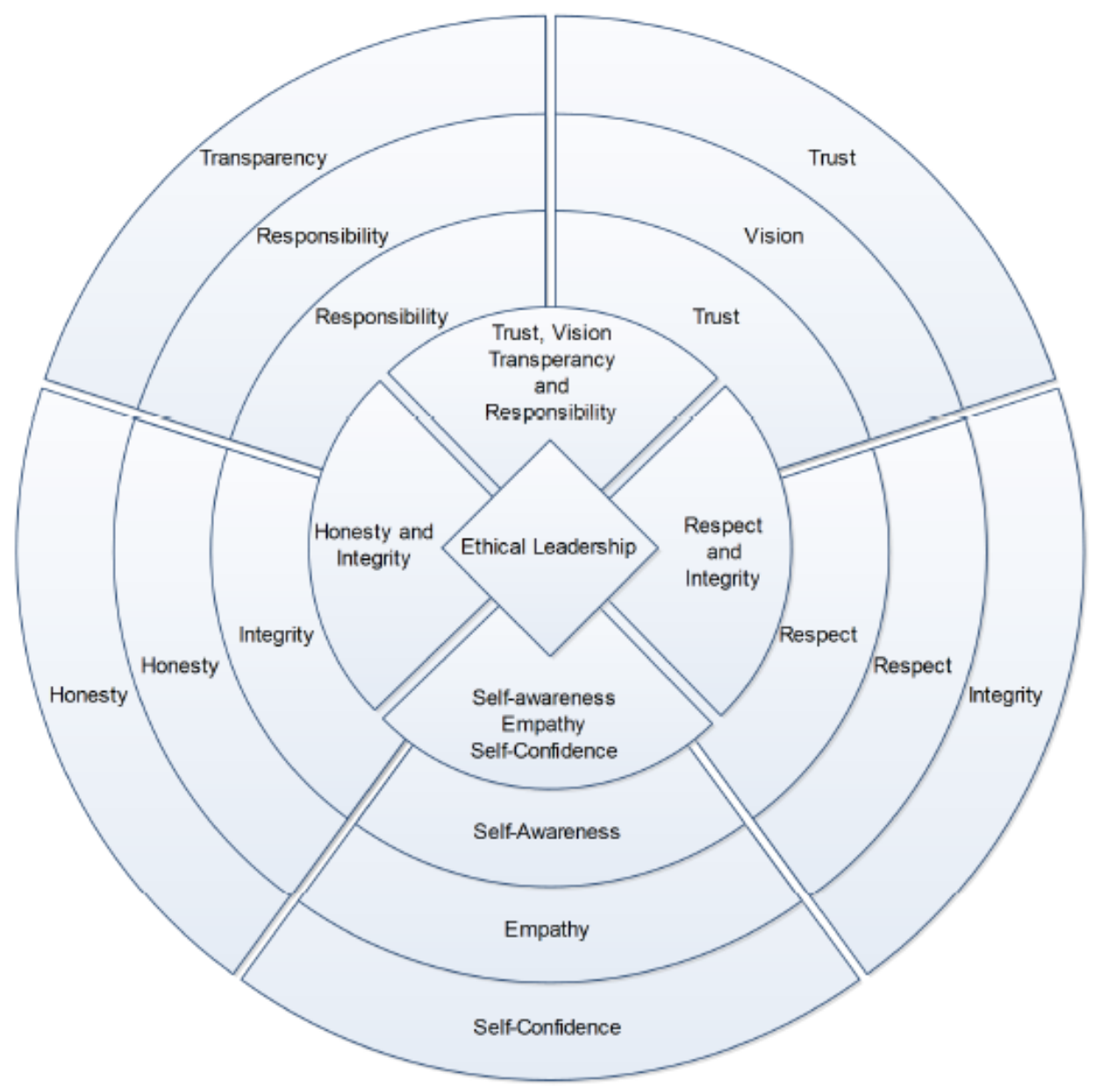

Figure 1: The values that resonated pre- and after leadership intervention program Source: Artwork by Theodora Issa 
The values that remained constant with the pre-and post-test were empathy, honesty, respect, vision and responsibility. The least held values were power and loyalty. The values that changed over a leadership intervention program were trust, respect, integrity, self-awareness and responsibility.

In other studies, similar values emerged across different instruments measuring both preferences and moral values (Resick et al., 2011; 2006). For example, Macnab and Fitzsimmons (1987) identified eight common factors across four instruments that measured work values as preferences for the type of work or work environment considered important in job decisions. These preferences include authority, co-workers, creativity, independence, security, altruism, work conditions and prestige. Instruments that measured moral values at work have also identified very similar constructs. For example, cross-national data from Asia, America and Europe, have identified similar themes in moral values such as integrity, respect, fairness, altruism, empowerment and collective orientation (Resick et al., 2006)

Despite this overlap in values, people were found to differ in terms of the relative importance assigned to each of these specific themes in their value system. For example, managers from different organizations generally agreed that values such as staff member involvement, responsibility, autonomy and cooperation, and traditional moral virtues such as honesty and decency, are important in their organization and in their own work (Brytting and Trollestad 2000). However, some managers have a stronger focus on the values of involvement and responsibility due to their respect of the basic human needs of involvement, and the employees' willingness and ability to take responsibility. Other managers, on the other hand, although still emphasized the importance of the same values of involvement and responsibility in their discussion, they also stressed the necessity of uniformity, reliability and loyalty to the organization as important organizational values.

The values that changed over a leadership intervention program were trust, respect, integrity, self-awareness and responsibility. 


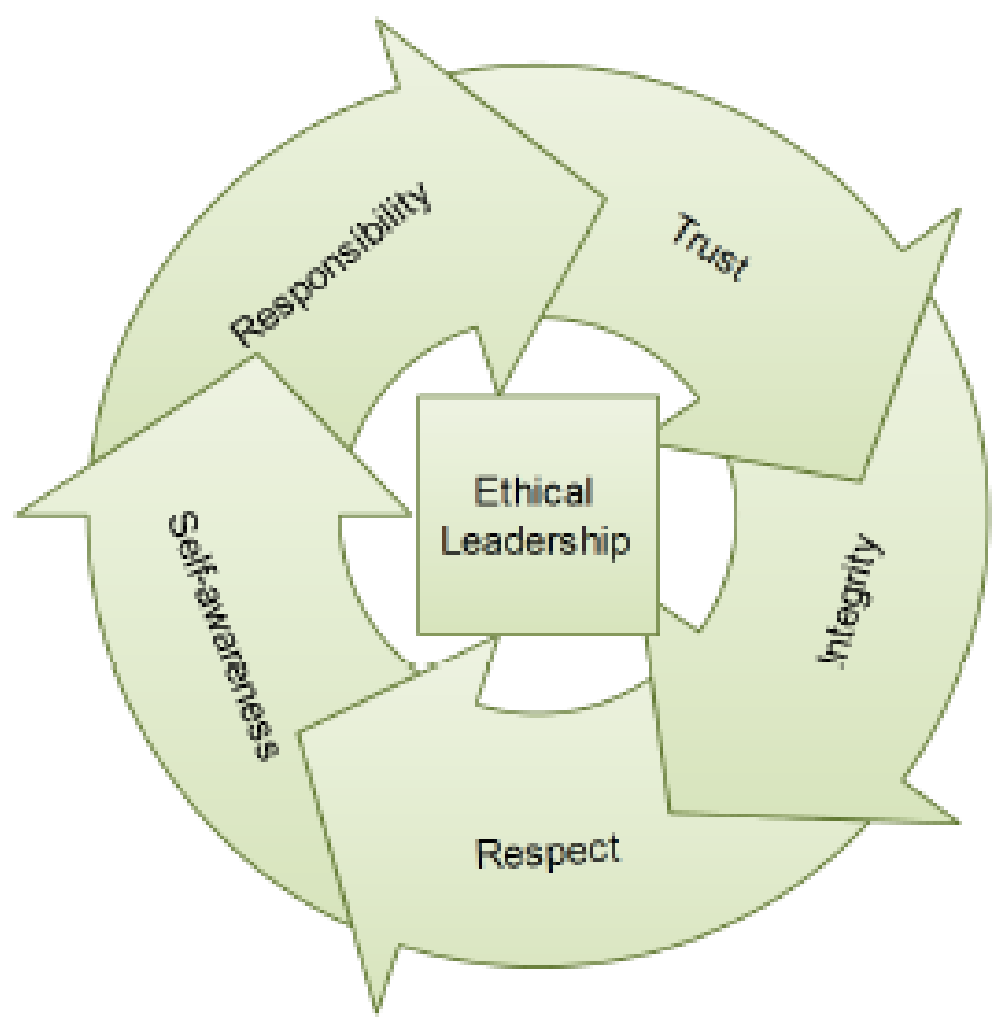

Figure 2: The values that changed over a leadership intervention program in relation to ethical leadership

Source: Artwork by Theodora Issa

Participants were also required to respond to other questions, such as 'explain how you believe you obtained these values. For example, was it through a particular relationship with someone or a defining experience?' Participants responded by stating:

'I believe my values are made up of a combination of family upbringing and influence and learning throughout my life.’

'As I have experienced certain situations, my original values learnt from my parents have been reinforced and I learn why these values are important. I believe these values differentiate me from others and make me the person I am today.'

Indeed, Fritzsche (1995) contends that personal values have long been associated with individual decision-making behaviours. Further, Issa and Kiffin-Peterson (2004) argue that empirically examining the relationship between individual differences and the values that these individuals hold could assist individuals and, in turn, businesses, to tackle the deterioration of ethics and ethical decision-making in business-related matters. Further, religion seems to have an influence on the values of some participants:

'I obtained these values through experience and being taught about them. Having been raised a Christian these values are taught to me.' 
Although this might be considered the norm in some countries, especially the United States, in a secular country like Australia, such values might not be appropriate to display in the workplace. As Hovey (2003) argues, there is an ongoing challenge for leaders to fuse Christian values in the Australian workplace.

The participants were also asked to describe how their values compare with their actions. For example, are they consistent or inconsistent with your actions? Why or why not? If they are inconsistent, what might you do to make your actions more consistent with your values? Where is it hardest for you to remain true to your values? What parts of these situations are the strongest deterrents to living out your leadership values? Responses were mixed, but the majority of respondents considered their values to be inconsistent with their actions:

'Inconsistent. I try to always check my performance ensuring it is consistent with my values.'

'Sometimes my values are inconsistent depending on the situation -sometimes I am forced not to be honest when the situation does not favour me.'

'Sometimes my values are inconsistent with my action. It depends on the situation at the moment. We cannot always use power to our members to get their respect. We trust and treat them fairly but there is a limit for that. We can't always be reliable.'

I would put the consistency of the values with my actions in percentage and $76 \%$ of the time they are consistent. The inconsistency comes or arises because of the pressure groups or environment that impedes these values.

These comments and indeed other studies lend support to the point that it is the situation that controls the values that managers enact. For example, Lowell (2012) concludes that it may be assumed that the levels of moral dissonance and the extent of rationalization/self justification amongst managers, are more a function of personality and situational factors.

Moreover, the participants were asked whether their personal values conflict with the organization's official/stated and actual/operating values. If these contradict, how do they? How do you reconcile this difference to yourself? If they do not conflict, explain how they are consistent and what this means to your future in the organization?

The respondents were keen to share their feelings with the researchers, stating:

'These values are equally important for the organisation.'

'My personal values are actually aligned with my employers documented values. However, there are people in the firm who obviously do not possess the same values and this disrupts the flow of the office and influences other people in the office - typically followers.'

'They are consistent with those of my organization because my organization values the same values as I do, and honesty plays a bigger part. I am [keener] to stay in such an organization because our values are the same.'

In this regard Suar and Khuntia (2010) argue that irrespective of the type of organization and age of managers, personal values more potently and consistently decreased unethical practices and increased work behaviours compared to value congruence. Hiring managers emphasizing personal values can demote unethical practices and promote ethical work behaviours.

Participants were also required to outline what actions or behaviours their values dictated with respect to leadership. How will they affect who you will try to be as a leader and how you 
will act and make decisions as a leader? The respondents were keen to provide responses in the following manner:

'My value of honesty will hopefully make me transparent to my co-workers and followers. This transparency will bring about a feeling of trust and loyalty within the environment. This in combination with my ability to motivate people should put me in good stead.

'These values will make me less likely to dictate terms to my team and be controlling. Greater attention will be paid to the needs of the team instead of being a dictator.'

'I think being honest is a good action for my leadership, and it will make me a good leader. The reason is because by being honest, people will know what I am thinking, and of course the people will also be honest to me to show what they feel. So by doing that we can know the strengths and the weaknesses of each other, and it's gonna [going to] be easy for us to solve the problem and make a better improvement.'

These comments by participants echo the work of Langlois and Lapointe (2010) who concluded that ethical training has an impact on students, which enhances the participants' understanding of the value of ethical leadership to cure the ills of the modern and contemporary society.

Indeed, it is worthwhile to conclude here with some of the participant's comments in relation to how they would foresee a leadership situation in which their values might conflict with one another?

'I think honesty and communication are currently conflicting in my current job as I am not being completely honest in my communication around my work pressures and high demand and work load. This may also be an issue when I am in a leadership role. I believe I need to learn skills in communication to best communicate my feelings at work ensuring I am both honest and empathetic to the receiver.'

'I am confident that these values are complimentary to each other. I cannot easily find a situation where they could contradict each other. Perhaps poor communication may result in a message that is interpreted the wrong way and therefore indicated disrespect. This point however proves that successful communication conveys and reassures others that a respectful relationship exists.'

Indeed, communication is key, and ethical leaders are considered to be good communicators. As Fry and Slocum (2008) argue, businesses need to develop new business models that accentuate ethical leadership, employee well-being, sustainability and social responsibility.

\section{Conclusion}

In this paper, we provided evidence in relation to the value of leadership intervention program. Data analysis was collected on pre- and post-leadership intervention values, such as integrity, honesty, trust, self-confidence and transparency were evident. Interventions, including personal reflection, formative learning and action research, had an impact on the way participants thought of ethical leadership, values and motivations. The results indicate values that evolved post-test, such as trust, respect, integrity, self-awareness and responsibility, with empathy, honesty, respect, vision and responsibility remaining consistent throughout the study. These results are in contrast to some prior research in this area including personal values, leaders actions and organizational values convergence to create congruence. Our findings indicate that multi- 
perspective, scaffolded learning is associated with significant levels of leadership reflection and self-awareness. Leaders with higher levels of reflection and self-awareness have significantly higher levels of motivation towards ethical behaviours which are generated from values.

Despite the paper's limitations, reporting on a sample of postgraduate students in one university and one country, this paper highlights the importance of exposing students to ethical values and considers the influence those values might have on the way students conduct themselves when they are in the workforce. This study is part of a larger longitudinal study that would allow more in-depth analysis through the collection of more data and using different techniques in the future. 


\section{REFERENCES}

Bahl, Kanika T. and Anubha, Dadhich. 2011. "Impact of Ethical Leadership and Leader-Member Exchange on Whistle Blowing: The Moderating Impact of the Moral Intensity of the Issue". Journal of Business Ethics 103 (3):485-496.

Baron, Jonathan 1981. Reflective Thinking as a Goal of Education. Intelligence 5:291-309.

Bartlett, Christopher A. and Paul W. Beamish. 2011. Transnational Management Text, Cases, and Readings in Cross-Border Management. 6th ed. New York: McGraw-Hill Irwin.

Basik, Kevin. and David. Keller. 2011. "The Consistent Importance of Character and Leadership In Action". Journal of Character and Leadership Integration 2 (1):3-5.

Beck, Ulrich;. 2002. "The Terrorist Threat: World Risk Society Revisited". Theory, Culture \& Society 19 (4):39-55.

Brytting, T. and C. Trollestad. 2000. "Managerial thinking on value-based management". International Journal of Value-Based Management 13:55-77.

Calderhead, James;. 1989. "Reflective Teaching and Teacher Education". Teaching \& Teacher Education 5 (1):43-51.

Collins, S., Arthur, N., and Wong-Wylie, G. 2010. "Enhancing reflective practice in multicultural counseling through cultural auditing". Journal of Counseling and Development, 88(3), 340-374.

De La Harpe, B. and Radloff, A. 1997. "Time spent working and studying in the first year: what do students tell us"? In R. Pospisil \& L. Willcoxson (Eds.), Learning Through Teaching. The Proceedings of the $6^{\text {th }}$ Annual Teaching Learning Forum, February 1997 (pp. 73 77). Perth, Australia: Murdoch University.

Demenchonok, Edward and Richard; Peterson. 2009. "Globalization and Violence: The Challenge to Ethics". American Journal of Economics and Sociology 68 (1):51-76.

Dewey, J. 1933. How we think: A restatement of the relation of reflective thinking to the educative process. Boston, Mass.: Heath.

Dose, J. J. 1997. "Work values: An integrative framework and illustrative application to organizational socialization". Journal of Occupational and Organizational Psychology 70:219-240.

Fritzsche, David J. 1995. "Personal Values: Potential Keys to Ethical Decision Making". Journal of Business Ethics 14 (11):902-922.

Fry, Louis W. and John W. Jr. Slocum. 2008. "Maximizing the Triple Bottom Line through Spiritual Leadership". Organizational Dynamics 37 (1):86-96.

Goleman, D., Boyatzis, R., and McKee, A. 2002. "The emotional reality of teams". Global Business and Organizational Excellence, 21(2), 55-65.

Gustafsson, C., Asp, M., and Fagerberg, I. 2007. "Reflective practice in nursing care: embedded assumptions in qualitative studies". International Journal of Nursing Practice, 13(3), 151-160.

Hannah, Sean T., Bruce J. Avolio, and Fred O. Walumbwa. 2011. "Relationships between Authentic Leadership, Moral Change, and Ethical and Pro-Social Behaviors". Business Ethics Quarterly 21 (4):555-578.

Holt, Svetlana, and Joan, Marques. 2012. "Empathy in Leadership: Appropriate or Misplaced? An Empirical Study on a Topic that is Asking for Attention". Jounral of Business Ethics 105 (5):95-105.

Hovey, Craig R. 2003. "Church on Sunday, Work on Monday: The Challenge of Fusing Christian Values with Business Life/Faith, Morals, and Money: What the World's Religions Tell Us about Ethics in the Marketplace". Theology Today 60 (3):440.

Issa, Theodora, and S Kiffin-Peterson. 2004. "The influence of Individual differences, Values and Spirituality on Ethical Decision-Making". Paper read at Australian and New 
Zealand Academy of Management (ANZAM), December 2004, at Dunedin, New Zealand.

Kalshoven, Karianne, Deanne N., Den Hartog and Annebel H. B. De Hoogh. 2011. "Ethical Leader Behavior and Big Five Factors of Personality". Journal of Business Ethics 100 (2):349-366.

King, P.M. and Kitchener, K.S. 1994. Developing reflective judgement: understanding and promoting intellectual growth and critical thinking in adolescents and adults. San Francisco: Jossey-Bass.

Kolb, D.A. 1984. Experiential learning. London: Prentice-Hall.

Langlois, Lyse;, and Claire; Lapointe. 2010. "Can ethics be learned? Results from a three-year action research project". Journal of Educational Administration 48 (2):147-163.

Light, G., Calkins, S., and Cox, R. 2009. Learning and teaching in higher education: the reflective professional. Los Angeles: Sage.

Lowell, Jonathan. 2012. "Managers and Moral Dissonance: Self Justification as a Big Threat to Ethical Management"? Journal of Business Ethics 105 (5):17-25.

Macnab, D., and G.W. Fitzsimmons. 1987. "A multitrait-multimethod study of work-related needs, values and preferences". Journal of Vocational Behavior 30:1-5.

Mann, K.V., Gordon, J., and MacLeod, A. 2007. "Reflection and reflective practice in health professions education: a systematic review". Advances in Health Sciences Education, 14(4), 595-621.

Metler, Craig. 2006. Action Research: Teachers as Researchers in the Classroom. Thousand Oakes: Sage Publications.

Mezirow, J. 1991. Transformative dimensions of adult learning. San Francisco: Jossey-Bass

Miles, M.B. and A.M. Huberman. 1994. Qualitative Data Analysis. Edited by 2nd. London: Sage Publications.

Muilenburg, Dennis. 2011. Interview: Mr. Dennis Muilenburg - CEO of Boeing Defense, Space and Security. Journal of Character and Leadership Integration 2 (1):53-57.

Palmquist, Michael, and Jill, Salahub. 2008. Content Analysis. Colorado State University 2006 [cited 26th November 2008 2008]. Available from http://writing.colostate.edu/guides/processes/writingsituations/representations.cfm.

Resick, C. J., P.J.; Hanges, M. W., Dickson, and J. K. Mitchelson. 2006. "A cross-cultural examination of the endorsement of ethical leadership". Journal of Business Ethics 63:345-359.

Resick, Christian J., Gillian S., Martin, Mary A., Keating, Marcus Dickson, W., Ho Kwong, Kwan and Chunyan, Peng. 2011. "What Ethical Leadership Means to Me: Asian, American, and european Perspectives". Journal of Business Ethics 101 (3):435-457.

Schon, Donald. 2005. Educating the Reflective Practitioner. Tom Russell, Queen's University, January 19981987 [cited 2nd September 2005 2005]. Available from http://educ.queensu.ca/ ar/schon87.htm.

Schon, Donald. 1987. Educating the Reflective Practitioner: Toward a New Design for Teaching and Learning in the Professions. Edited by Jossey-Bass. First ed, Jossey-Bass higher education series. London, San Francisco,: Jossey-Bass Inc.

Schon, Donald. 1991. The Reflective Practitioner: How Professionals think in action. 2nd Edition ed. London: Avebury, Ashgate Publishing Limited. Original edition, 1983.

Schon, Donald A. 1983. Reflective Practitioner - How Professionals think in action. Cambridge: Basic Books Inc.

Suar, Damodar and Rooplekha, Khuntia. 2010. "Influence of Personal Values and Value Congruence on Unethical Practices and Work Behavior". Journal of Business Ethics 97:443-460.

Stedmon, J. and Dallos, R. 2009. Reflective practice in psychotherapy and counselling. Maidenhead: Open University Press. 
Tumasjan, Andranik, Maria, Strobel and Isabell, Welpe. 2011. "Ethical Leadership Evaluations After Moral Transgression: Social Distance Makes the Difference". Journal of Business Ethics 99 (4):609-622.

Valle, Matthew. and David. Levy. 2011. "Abusive Supervision in the Armed Forces: Bad Character and Leadership: Exploring the Consequences of Abusive Supervision in the Armed Forces". Journal of Character and Leadership Integration 2 (1):7-15.

Wong-Wylie, G. 2006. "Narratives of developing counsellors' preferred theories of counselling storied through text, metaphor, and photographic images". The Qualitative Report, 11(2): 262-301

Zubizarreta, J. 2009. The learning portfolio: Reflective practice for improving student learning (2nd ed.). San Francisco, CA: Jossey-Bass A Wiley Imprint.

\section{ABOUT THE AUTHORS}

Prof. Kandy Dayaram: Senior Lecturer in the School of Management at Curtin University, Australia.

Dr. Theodora Issa: Lecturer in the School of Management at Curtin University, Australia. 
